NASA Technical Memörändum 88354

\title{
A Look at Handling Qualities of Canard Configurations
}

\section{Seth B. Anderson}

(BASA-TH-88354) A ICCK AT HAXCLING CCALIIIES OF CAAAED CCNEIGUELTICNS $49 \mathrm{p}$ Avail: NTIS HC A03/BE A01
(NASA)

CSCL O1A

\author{
$187-22629$ \\ $\begin{array}{ll}\text { 63 } & \text { Onclas } \\ & 0076329\end{array}$
}

LIBRARY COPY

$$
\because 2 \quad 1950
$$

LANGLEY RESEARCH CENTER

LIBRARY, NASA

HAMPTON, VIRGINIA 


\section{A Look at Handling Qualities of Canard Configurations}

Seth B. Anderson, Ames Research Center, Moffett Field, California

September 1986

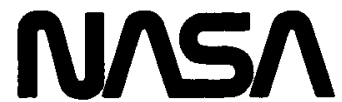

National Aeronautics and

Space Administration

Ames Research Center

Moffett Field, California 94035 


\title{
A LOOK AT HANDLING QUALITIES OF CANARD CONFIGURATIONS
}

\author{
Seth B. Anderson* \\ NASA Ames Research Center, Moffett Field, California
}

Abstract

The first human-powered flight was achieved by a canard-configured aircraft (Wright Brothers). Although other canard concepts were flown with varying degrees of success over the years, the tail-aft configuration has dominated the aircraft market for both military and civil use. This paper reviews the development of several canard aircraft with emphasis on stability and control, handling qualities, and operating problems. The results show that early canard concepts suffered adversely in flight behavior because of a lack of understanding of the sensitivities of these concepts to basic stability and control principles. Modern canard designs have been made competitive with tail-aft configurations by using appropriate handling qualities design criteria.

\section{Introduction}

A wide variety of canard designs have been proposed and flown over the years with varying degrees of success. 1 Recently, the canard arrangement has

Presented at AIAA 12th Atmospheric Flight Mechanics Conference, Snowmass, C0, August 19-21, 1985.

*Associate Fellow AIAA. 
shown a sharp rise in popularity, starting in the home-built (experimental category) and carrying on to military fighters and short-haul commuter designs. There may be several reasons for a change in popularity of a particular aerodynamic concept, including (1) the potential for increased performance in terms of an expanded high/low speed operating range or increased maneuverability (tied in with mission requirements); (2) newly available structural materials that favor a specific design layout (use of aeroelastically tailored composites); and (3) potential improvements in handling qualities for safer operating characteristics (better stall behavior).

Recent articles in the popular press have extolled the virtues of canards, pointing out that because canards provide positive lift, a higher $C_{L_{\max }}$ results, the aircraft can be smaller with less drag, and safety is improved because of natural aerodynamic angle of attack (AOA) limiting. Other more technical papers ${ }^{2}$ which have examined optimization of canard designs based primarily on performance have indicated no advantage of foreplanes when normal stability and structural weight considerations are accounted for. Although a canard-configured aircraft was the first recognized successful example of human-controlled powered flight (Wright Brothers), tail-aft designs have dominated the aircraft market for both military and civil use for reasons which are not readily apparent. In recognition that many tradeoffs are involved in optimizing a given concept, this paper concentrates on handling qualities of the canards since this factor strongly influences pilot acceptance. By examining the handling qualities of canard configurations, a clearer understanding of the relative merits could evolve along with some feeling for future trends.

The scope of the paper includes an initial discussion of the basic stability and control requirements needed for both canard and aft tail designs 
with particular concern for the interrelationship with performance. After guidelines are established for desired handling qualities, a review is made of selected canard aircraft to reflect on reasons for the success or failure of some types.

\section{Discussion}

In the first part of the discussion, factors that influence stability and control are reviewed in a general sense to show how various levels of stability and control relate to pilot opinion of aircraft response. In discussing the effects of fore or aft tail location, primary emphasis is placed upon longitudinal (pitch) characteristics, recognizing that lateral/directional behavior can be influenced also by tail placement.

\section{Stability and Control Considerations}

Stability can be obtained for any planform configuration by locating the center of gravity (c.g.) ahead of the aerodynamic center (a.c.). The c.g. range available is configuration-dependent and is affected by tail size (area) and location. In a stable conventional aircraft, the forward c.g. limit is determined primarily by the ability of the tail to raise the nose wheel for lift-off. The aft c.g. location is determined by stability considerations usually slightly ahead of the neutral point. The adverse consequences of a c.g. Location too far aft can arise insidiously; the aircraft may diverge (slow up) from the trim speed to the stall where in some cases full nose-down pitch control will not increase airspeed (lower $A O A$ ) and provide a safe recovery, particularly at low altitude. For a canard configuration, the forward c.g. location could remain the same provided similar tail area and moment arm 
are used. However, since the canard effectively moves the center of lift forward, the c.g. range for stability is considerably reduced. Increasing canard area moves c.g. limits forward and increases the available c.g. range. Geometric considerations result in the practical c.g. range being located ahead of the wing leading edge with the canard carrying a greater unit load than the wing and demanding a relatively high $C_{L_{\max }}$. To reduce its destabilizing effect, a low lift curve slope would be desired with due consideration to induced drag of this heavily loaded surface. Historically, it has not been feasible to provide sufficient trim capability to use wing flaps on a canard aircraft, and flatter approach angles are common.

Dynamic longitudinal stability characteristics also depend upon configuration layout and c.g. location. They are important to the pilot because of concern for possible oscillatory divergences in AOA or airspeed when the aircraft is disturbed. Many studies have examined the effect of variations in dynamic stability and damping on precision of flight path control. The data in Fig. 1 summarize pilots' comments ${ }^{3}$ of the effects of variations in stability with damping. The results indicate that an aircraft is most pleasant to fly when stability levels are neither too high nor too low and sufficient damping is available.

Although it is generally agreed that positive stability is desirable, neutral or negative stability is not categorically disastrous. The amount of pilot attention required for control increases as static stability decreases and the pilot must add "lead" to the control inputs, thereby increasing workload. The degree of instability permissible for safe operation depends upon several interrelated factors, including the type of aircraft, mission, task, amount of turbulence, pitch damping, etc. Pilot opinion ${ }^{4}$ relating to control of an unstable aircraft in landing approach is shown in Fig. 2 in 
terms of the variation in pilot rating with time to double amplitude $\left(\mathrm{T}_{2}\right)$. $\mathrm{A}$ rapid deterioration in pilot rating occurs as stability is decreased because the pilot must constantly devote his or her attention to attitude control. Note that in these tests periods greater than approximately $6 \mathrm{sec}$ showed no significant improvement in pilot rating nor was a satisfactory rating ever obtained for the basic aircraft (no artificial pitch damping provided).

Tail-plane location can significantly affect stall characteristics, from the standpoint of providing satisfactory stall recovery control and adequate stall warning. Specifications governing stall behavior require the aircraft to have mild roll, pitch, and yaw motions (less than $20^{\circ}$ ) in stalled flight. In addition, it is desired that no pitch-up tendencies occur, and it should be possible to prevent and recover from the stall by moderate use of the pitch control alone. The stall approach should be accompanied by an easily perceptible warning (shaking of the cockpit controls, buffeting or shaking of the airplane, or a combination of both).

Although stall usually corresponds to maximum lift coefficient, lowaspect-ratio planforms may have extremely nonlinear lift curve slopes where buffet, wing rock, directional divergence, and Dutch roll oscillations may precede the $A O A$ for $C_{L_{\max }}$ by over $20^{\circ}$ to $30^{\circ}$. When a control limit sets minimum permissible speed, some indication or warning of the impending lack of flight path control may not occur. A problem may result when an aircraft encounters a second stable trim point at high AOA where reduced control effectiveness may not provide recovery to unstalled flight. For most canard configurations, the foreplane is designed to reach its maximum lift capability before the wing stalls to prevent pitch-up. Of course, dangerously high AOA 
penetrations can occur even with good canard airfoil aerodynamics if the aft c.g. Iimit is violated.

With the aformentioned stability and control (handling qualities) considerations in mind, it is of interest to briefly examine several canard aircraft and reflect on the reasons for success or failure of some types.

\section{Historical Overview}

The popularity of canard concepts has fluctuated over the years. At the start of powered flight, most new aircraft copied the Wright Brothers canard design; however, only tail aft configurations were produced during the WW I years, 1914-1918, and only a few copies of canard designs invaded the market for the next 50 years. In those early days of flight, most aircraft were designed and built without the benefit of wind tunnel tests, and documentation of stability and control characteristics did not exist. The first systematic stability and control flight test results were conducted by $\mathrm{NACA}^{5}$ in 1919 using a Curtiss JN4H aircraft. Handling qualities measurements correlated with pilot opinion did not take place until the late 1930 s. 6

Although a great number of canard-equipped aircraft have flown throughout the years, it is only recently that stability and control data have become available to provide a clearer understanding of the relative merits of this concept. As a result, only a select few of the many canard concepts that have demonstrated successful flight are reviewed.

In the early struggles to achieve powered flight, the canard concept proved to be popular. The Wright Brothers designed their 1903 canard "Flyer" by appropriately blending knowledge of structures, power plant, and aerodynamics to construct a machine that had enough power to offset the drag and 
sufficient control to trim over a wide $A O A$ range. They did not, however, understand or appreciate the need for stability and this was reflected in problems encountered in developing their concept. Not only was their aircraft unstable longitudinally and laterally, but also the elevator hinge moments were overbalanced, and large adverse yaw complicated turn entries.

An examination of a two-view drawing of the 1905 aircraft (Fig. 3) reveals features which are of special interest from the stability and control (handling qualities) standpoint. Foremost is the use of the foreplane, which led to the configuration coined "canard," a French word for a hoax or tall story. In fact, their accomplishment of powered flight was not completely believed until Wilber Wright demonstrated their aircraft in many European countries in 1908. The reason for the choice of the canard control was not based upon measured data (the Wrights' wind tunnel tests did not include pitching moment), but more upon intuitive reasoning. Good control was uppermost in their minds. 7 Wilber had expressed a concern that an aft tail configuration had an intrinsic danger that was associated with Lilienthal's loss of control and death while flying his glider in 1896.

The stall behavior of their aircraft was never well documented. The relatively constant chord planform would normally provide good stall characteristics by virtue of center-section flow breakdown, except that downwash from the canard would unload the wing root area and tend to cause loss of lateral stability at stall. Stalls had been encountered in the 1901 glider (configured similarly to the 1903 powered vehicle), which was observed to "mush" to the ground with little damage. A more serious stall did occur with the 1903 Flyer when Wilber allowed the aircraft to pitch up to the stall in a moment of confusion when he inadvertently stopped the engine. The stall occurred at low altitude, resulting in a nose-down impact with considerable 
damage, but Wilber was not hurt. The nose-down behavior is normally a desired stall recovery response, except when flying close to the ground.

Pursuing the pitch characteristics further, recent data ${ }^{8}$ obtained on a one-eighth-scale model show that pitching moment characteristics were relatively linear up to $\mathrm{C}_{\mathrm{L}_{\max }}$. In fact, a pitch down at the stall normally associated with a canard control losing effectiveness (by stalling before the wing) is not evident. Flight stall behavior would be altered by the c.g. location used. In the Wrights' case, the c.g. was not far enough forward to highly load the canard and cause it to stall first. Although the Wrights may have wanted more stability, it was not possible to move the c.g. farther forward because of the inability to trim out the large nose-down pitching moment associated with the highly cambered airfoil. It should be noted that even though the flyer was highly unstable, a large upload on the canard was required to provide trim at a cruise $C_{L}$ of approximately 0.6 .

The Flyer's instability was a major handling qualities problem as evidenced from comments by Orville Wright in a letter to Wilber in 1909. "The difficulty in handling our machine is due to rudder (horizontal tail or canard) being in front, which makes it hard to keep on a level course. If you want to climb you must first give the front rudder a larger angle, but immediately the machine begins to rise you must reverse the rudder and give a smaller angle. The machine is always in unstable equilibrium. I do not think it necessary to lengthen the machine but to simply put the rudder behind instead of before." From the recent wind tunnel data it was estimated that they were flying with a negative static margin of approximately $-20 \%$. The derived pitch dynamic stability showed that the short period mode was aperiodic and doubled amplitude in about $0.5 \mathrm{sec}$. This calculated divergence rate is considerably greater than that judged acceptable from the data shown in 
Fig. 2. In reality, the behavior would be subdued by apparent mass and inertia effects. A skilled pilot could learn to cope with this behavior, but undoubtedly the pilot workload was high.

As their flights progressed, the Wrights recognized the need for more stability. By reducing the wing camber and providing a more favorable hinge moment balance, they were able to add $70 \mathrm{lb}$ of cast iron at the nose to improve stability. Eventually, one of the canard surfaces was moved to the rear and made movable, improving stability so that hands-off flight was possible.

The lateral/directional stability and control of the Flyer were marginal and early attempts at turning flight were fraught with danger. In fact, it was not until September 1904 that a $360^{\circ}$ turn was accomplished. Part of the problem was lateral stability. Although dihedral invented by Cayley ${ }^{9}$ around 1800 was known to produce positive lateral stability, the Wrights chose to use anhedral because their glider experiments had shown adverse bank angle effects when flying in ground effect in cross wind operation with positive dihedral. Although anhedral tended to help the airplane turn by virtue of an unstable spiral mode, wilbur noted in his diary, "Unable to stop turning." It was fortunate that directional stability $\left(\mathrm{C}_{\mathrm{N}_{B}}\right)$ was neutral to low, since a large $\mathrm{C}_{\mathrm{N}_{B}}$ would have aggravated the spiral instability. In part, the poor yaw (turn) behavior was due to the interconnect system used to improve turn entry. The Wrights discovered early in their glider tests that wing warping provided good roll effectiveness, but it also produced adverse yaw. By interconnecting the rudder with wing warp, adverse yaw effects were reduced, but yaw control power was marginal. In 1905 they decided to operate the rudder control independently with improved turn capability. 
Although the 1903 Flyer did achieve success in ushering in the era of powered flight, the canard concept did not appear to have enough merit to prevail beyond 1910. The 1911 model B aircraft had a conventional (aft) tail. One of the historically prominent canard designs was the XP-55 Curtiss fighter. The tail-first pusher, called "Ascender", was one of several novel designs that stemmed from a 1940 Army Air Corps request to generate new, highperformance, unorthodox fighters which would be superior to the best European designs. A three-view drawing of this concept (Fig. 4) and an in-flight view (Fig. 5) reveal several advanced aerodynamic features which were unproven from a handling qualities standpoint in the early 1940s. These included a lowaspect-ratio, all-moving canard pitch control, a moderately swept wing, and rudders mounted near the wing tips. The foreplane location was not selected primarily for good stall behavior (discussed later), but for pitch control, improved visibility, and more efficient gun installations. It should be appreciated that this aircraft was designed without the benefit of adequate handling qualities specifications to cover high AOA behavior. Wing sweep was incorporated, not for transonic flow benefits (drag reduction), but to provide an aft location for the vertical fins for directional stability and control.

of the many handling qualities deficiencies, the most infamous was its ominous stall behavior. The slow, steady approach to the stall was considered satisfactory in that the canard surface lost nose-up trim effectiveness with increasing $A O A$ and the aircraft pitched down for stall recovery. In a dynamic pull up to the stall, however, the XP -55 pitched down abruptly to an inverted position which defied recovery. On this occasion, the engine stopped, and after losing $16,000 \mathrm{ft}$ in a vertical free fall, the pilot safely escaped (no ejection seat available). The inverted highly stable "deep stall" trim point had been predicted by small-scale wind tunnel tests. The near-vertical (high 
negative $A O A)$ flight path is attested to by the nearly intact inverted aircraft wreckage (Fig. 6).

To improve the poor high $A O A$ behavior, a second Ascender was modified with extended wing tips, wing fences, and small "trailerons" outboard of the wing-mounted rudders. The stall behavior of the "improved" XP-55 is best described by the following comments made by pilot Brig. Gen. Benjamin S. Kelsey, USAF (Ret.). 10

"The slow, steady stall was quite satisfactory, and the plane behaved normally in the usual intentional maneuvers. Because some aircraft have different characteristics when a stall is initiated abruptly, I tried a sharp pullup. The nose came up rapidly to a very high angle, and forward nose-down control was ineffective in checking the pitch-up. What happened next was a series of completely confusing out-of-control gyrations. Eventually a wobbly sort of spin developed from which recovery was possible.

"After trying a few more violent stalls, all of which went through the same out-of-control contortions, I thought I knew what happend, but I am still not sure. Initially the plane, without the damping of a conventional tail to slow the rate of pitch, came up to such a steep angle that the forward elevator could not be moved enough to get any down force on the nose. What must have followed was a stall with the nose pointed nearly straight up. This much and the beginning of a rolling motion was fairly clear.

"Assuming that with the swept wing, one side or the other stalled first, the plane did a kind of twisting cartwheel, first rotating about the fuselage and then pivoting on one wingtip. As 
it went over the top in something like a hammerhead stall, the top advancing wing seemed to roll the plane partially onto its back. This rotation of the aircraft about its fuselage axis and in the plane of the wing was like an autorotation spin except that the axis of the spiral was falling through the horizontal so that it was probably more nearly a very wobbly snap roll. With the rudder surfaces located on the wingtips and the fin surface close to the center of gravity over the engine, these vertical surfaces weren't effective in slowing the spinning.

"All of this occurred in very rapid sequence, and nothing was effective until a recognizable spin had developed. If one visualizes the movements of outside references--the horizon, sky, and earth--it will be readily apparent that the pilot was in no position to provide a precise description of what went on."

This aircraft has the potential for an unusual out-of-control dynamic pitch behavior, "tumbling," which has been identified by model tests 11 for some concepts during World War II (WW II). Tumbling, defined as a sustained autorotative pitching motion, has been found to more likely occur for tailless and tail-first (canard) configurations with low pitch inertia, low pitch static stability, and high-aspect-ratio wings. Conventional (tail-aft) configurations could not be made to tumble in model tests. Tumbling was initiated from a nose-up attitude $\left(A O A=-180^{\circ}\right)$ to simulate a whip stall. Tests showed that the XP-55 model would pitch down and sustain an irregular tumbling motion regardless of pitch control position. Increasing the size of the canard surface had a detrimental effect on tumbling, suggesting that pitch damping was not the primary factor involved. Rather, the decrease in pitch 
stability caused by adding area head of the c.g. appeared to dominate the tumbling tendency. It would be expected that lateral or directional control inputs causing asymetry in the lateral/directional axes would induce motions similar to those described in stall recovery attempts.

This aircraft configuration was even more amazing when one considers that swept-wing technology had not been "discovered" yet. It was 1945 before U.S. engineers visited Germany and noted that swept-wing planforms were being used to reduce transonic flow-separation problems (drag rise) on aircraft such as the ME163. Low directional stability, a lightly damped Dutch, roll mode, and poor pitch dynamics all contributed to the demise of the XP-55 aircraft. In retrospect, it was unfortunate that the higher subsonic Mach number characteristics could not have been explored, allowing the U.S. to demonstrate the well-proven performance benefits of swept-wing technology. Although not a success, the XP-55 canard should be given credit for being the first fighter to identify the deep stall problem, an event not to be encountered by another fighter until some 15 years later.

The next canard concept, the VariEze, designed in 1974, incorporated several advanced design features which shared in establishing a new wave of popularity for the canard concept. In addition to the use of composites for smooth (low-drag) contours, the canard and wing system was carefully designed to provide passive stall control by limiting the ability to trim above the $A O A$ for wing stall. Notable features shown in a three-view drawing (Fig. 7) include a high-aspect-ratio canard mounted slightly above the wing chord plane, a considerable amount of wing sweep, and winglets for directional stability and control. This design, which is very compact (minimum wettedarea drag), has good performance and handling qualities. 
The VariEze aircraft had few stability and control problems over its development history. An early version employed both pitch and roll control on the canard to simplify control layout. This elevon control system was discarded because of roll-control problems. Early flight experience showed that relatively minor rigging errors in setting wing incidence and inadvertent built-in twist could overpower the available roll control. ${ }^{12}$ In two cases, full roll control and rudder assist was required to remain upright in first flights around the pattern. In another case, during landing approach in turbulence, the pilot required large simultaneous roll and pitch commands for flight path adjustments. Because of the inherent limitations in providing large rolling moments with full elevator control, the aircraft was damaged in touchdown. Incorporating roll control on the canard is basically less efficient because of an adverse downwash influence on the main wing opposing the canard rolling-moment input. Moving the ailerons to the main wing greatly improved roll control power even though an inboard aileron location was used.

The potential danger of serious stall departure can occur when c.g. location is mismanaged for either tail aft or canard configurations. An aft c.g. position for early models of the VariEze allowed greater penetration into stalled flight than desired. In several cases divergent wing rocking or rolloff occurred as speed was reduced in the landing approach. As would be expected, if $A O A$ is increased on the rear swept wing, outboard flow of the boundary layer would induce flow separation on the outboard wing area causing roll-off or pitch-up. A "fix" was obtained by protecting the outboard wing area by reenergizing the boundary layer by a leading edge droop (discontinuity) or a leading edge fence. 
In general, the handling qualities of the VariEze aircraft have been above average. The reasons for this have been documented by tests ${ }^{13}$ in the Langley $30-$ by $60-f t$ tunnel discussed next.

As noted previously, the placement of the canard, the airfoil section employed, and canard geometry are key factors in providing good low-speed behavior. The pitch stability characteristics of Fig. 8 show three areas in the $A O A$ range where important flow effects occur. The first change occurred at a relatively IOW $A O A$ of approximately $4^{\circ}$ where outboard flow of the boundary layer degraded the lift of the wing, slightly reducing stability. The second change in stability occurred near $14^{\circ}$ AOA where a significant increase in stability resulted from canard stall and the associated reduction in downwash over the inboard wing area. This increase in nose-down pitching moment provides the desired passive stall limiting. A third change in stability at $22^{\circ}$ AOA is destabilizing (nose up), resulting from outboard flow separation on the wing.

Canard pitch effectiveness is primarily a function of geometry (aspect ratio) and airfoil section. A gradual (trailing edge) flow separation pattern occurs on the VariEze canard at an AOA sufficiently below wing stall. The effect of airfoil section on canard stall lift characteristics is important. For example, a more abrupt stall (and lower $\mathrm{C}_{\mathrm{L}_{\max }}$ ) would occur with a NACA 0012 airfoil section. The gradual increase in lift beyond $C_{L_{\max }}$ for this airfoil could cause a post-stall pitch-up tendency. With a rearward c.g. position, a high AOA trim (deep stall) condition may occur from which recovery may be impossible.

With the usual canard-wing planform geometry typified by the VariEze aircraft, one might expect reduced directional stability and damping because of the short moment arm to the vertical tail. Although increasing wing sweep 
would improve directional characteristics, pitch stability and low-speed performance would suffer adversely. For the VariEze, a marked reduction in directional stability occurred in the $A O A$ range of $10^{\circ}$ to $20^{\circ}$. Dihedral effect, $C_{\ell_{B}}$, increased by a factor of 4 in the $A O A$ range from 0 to $20^{\circ}$. The combination of low $C_{N_{B}}$ and large $C_{\ell_{B}}$ should result in a high roll to yaw, lightly damped Dutch Roll behavior. This has been manifested in wing rock control problems at low approach speeds for early models.

Aileron effectiveness deteriorated markedly in the higher AOA range (above $10^{\circ}$ ); this would be expected with the inboard location of the ailerons as a result of the outboard boundary layer flow near the wing trailing edge inherent in swept planforms. Rudder control effectiveness is relatively low compared to a typical conventional configuration and also decreases markedly in the higher $A O A$ range. This may compromise crosswind landing behavior both in terms of the ability to achieve large steady state sideslip angles and to decrab for touchdown.

A fourth interesting canard configuration using a relatively large foreplane is shown in a three-view drawing (Fig. 9). This aircraft, the PAT-1 "Pugmobile" was designed as a production airplane (not experimental) using composite structure providing a very smooth (low-drag) external surface. The aircraft employs an aft low wing, tapered, with some leading edge sweep. The foreplane, approximately one-third the wing area, has a full-span slotted elevator for pitch control.

As will be shown, this layout inherently has a great challenge in meeting pitch trim and control requirements because the foreplane and elevator control is located to a large extent in the propeller slipstream. The majority of canard aircraft use rear-mounted engines for many reasons (performance, noise, etc.). Also, it is less difficult structurally to attach the foreplane to the 
fuselage in an area away from the engine compartment, and pitch trim changes with power variations are reduced. Large trim changes occur for forward c.g. locations when the canard is more highly loaded as in landing approach where more power is used. The pitch trim change with power can be reduced by employing a high-aspect-ratio (large span) canard where the elevator captures a smaller percentage of slipstream area as evidenced in some tandem-wing designs.

This aircraft configuration exemplifies potential stability and control problems at stall. Most canard concepts provide inherent stall-limiting such that the wing remains unstalled with satisfactory pitch behavior and control. It should be noted, however, that these highly desirable stallresistance characteristics depend upon the correct selection of certain design variables for the foreplane, including airfoil shape; geometry (aspect ratio, chord); relative location of the canard and wing; and, most important, c.g. location.

In order to more clearly understand the aerodynamic stability and control characteristics of canard configurations like the PAT-1, a one-third scale model of a canard-configured general aviation aircraft was tested ${ }^{14}$ in the $30-$ by 60-ft Langley Research Center tunnel. Tests indicated satifactory stall behavior at the forward c.g. location. With power-off, the configuration was stall-resistant in that longitudinal stability increased strongly as the canard stalled $\left(A O A=12^{\circ}\right)$ and reduced pitch control effectiveness occurred with increase in $A O A$. Although power-on tended to promote a pitch-up prior to canard stall, reduced control effectiveness limited the maximum obtainable $A O A$ to $12^{\circ}$ (less than wing stall).

With a rear c.g. location, the inherent passive stall-limiting features of the canard essentially disappeared at high AOA, and pitch stability and 
post-stall control recovery suffered adversely. Pitching moment data presented in Fig. 10 for various elevator deflections with power-off show a marked reduction in nose-down pitch-control power at post-stall AOA, but sufficient nose-down control was still available for recovery for the poweroff condition. Adding slipstream effects (power-on), however, further deteriorated stall behavior and post-stall control recovery characteristics. As indicated in Fig. 11, a stable "deep stall" trim area existed in the AOA range from $40^{\circ}$ to $60^{\circ}$. Full nose-down control $\left(A O A=-20^{\circ}\right.$ ) produced a small recovery moment near $60^{\circ} \mathrm{AOA}$; however, as $\mathrm{AOA}$ decreased to about $50^{\circ}$, the recovery moment was essentially zero. As noted, power reductions would help promote recovery from the high $A O A$ region.

A clearer understanding of the adverse stability and control behavior due to power were obtained from flow visualization studies. For propeller windmilling (power-off) conditions, flow separation began at the canard-fuselage juncture, starting at $6^{\circ} \mathrm{AOA}$, and spread rapidly spanwise to an abrupt stall over the entire canard span at $A O A$ of $12-14^{\circ}$. Wing flow separation started near the trailing edge at $14^{\circ} \mathrm{AOA}$ with an abrupt outer wing panel stall at $18^{\circ}$. With power-on, the slipstream promoted attached flow at the canardfuselage juncture and on the wing inboard areas; however, a more abrupt flow separation occurred for both surfaces at high AOA. These flow separation patterns are such that in the AOA range of wing stall, propeller slipstream increased canard lift at a given alpha and the resulting increased downwash on the wing tended to decrease overall stability.

The lateral/directional characteristics of this configuration are also of interest because of canard-induced flow effects at high AOA with power-on. A relatively large directional trim change occurs in the $A O A$ range for wing stall along with a marked reduction in rudder control effectiveness and 
directional stability in the post-stall region. These poor directional characteristics result primarily from the low-energy stalled wing wake impinging on the vertical tail. Lateral control effectiveness was reduced at large AOA values because of flow separation in the area of the inboard ailerons. Power effects tended to produce asymmetric wing stall and reductions in lateral stability. The combined reductions in lateral and directional stability and control in the post-stall AOA range would adversely affect recovery in the deep-stall region.

In summary, the example aircraft configuration clearly points out the potential problems lurking at rear c.g. locations where various design variables can interact adversely to promote poor stall behavior.

The MacCready Gossamer Albatross human-powered canard is of special interest because of unique stability and control characteristics. The aircraft geometry shown in a three-view drawing (Fig. 12) was chosen to maximum performance (low power required), and requirements for positive stability were ignored. Providing adequate controllability, which was a prerequisite from the onset, turned out to be difficult to achieve. 15 To quote one of the designers, "...control of the large wing at these speeds proved to be an elusive, challenging, and frequently disheartening quest." Because flight speeds were low $(3-5 \mathrm{~m} / \mathrm{sec})$, and calm air conditions were selected for flight tests, control which would be required for upsets caused by turbulence was essentially zero. The fact that the aircraft turned out to have neutral stability about all axes helped ease the controllability problem.

Pitch control of the canard surface was adequate, but only over a narrow speed range between minimum power speed ( 3 to $5 \mathrm{~m} / \mathrm{sec}$ ) and that for maximum trim lift capability $(6$ to $8 \mathrm{~m} / \mathrm{sec})$. Canard incidence was set lower than the wing to reduce trim drag. This resulted in the wing stalling first without 
warning at about $10 \mathrm{mph}$. Maximum power (hard pedaling) and forward pitch control produced a slow stall recovery with an altitude loss of about $10 \mathrm{ft}$. Penetrations to higher $A O A$ (more dynamic stall) resulted in a higher sink rate (parachute-like) which could not be arrested sufficiently to prevent damage when performed near the ground. Pitch dynamics, although neutrally stable, presented no control problems primarily because of high pitch damping.

Directional stability was essentially zero to slightly negative, which in effect was beneficial to improve turn entries. The addition of more vertical area, increasing directional stability and yaw damping, did little to improve the lateral control (turn capability) problem, which essentially paced development of the vehicle. Bank angle control to correct for turbulence and for turn entry could not be obtained by conventional techniques. Spoiler deflection at the wing tip momentarily caused a small yawing velocity, which was heavily damped, and the increased drag was unacceptable. Ailerons at the wing tips proved to be very ineffective in producing bank angle change, largely because of apparent mass effects which increased the apparent moment of inertia by a factor of five over the actual mass moment of inertia. In other words, the normal force produced by aileron deflection had to move (and accelerate) a cylinder of air equal to the wingspan in rolling the vehicle about the longitudinal axis--essentially very difficult at the low dynamic pressure available at cruise speeds.

The method of obtaining turn entry by tilting (rolling) the canard had been used in the very early years of flight, and this method proved effective for the Gossamer Albatross in coordinated (yaw-roll) heading changes up to $20^{\circ}$. Attempts to obtain larger heading changes by canard tilt alone were unsatisfactory because of adverse yaw-roll coupling, which increased sideslip and undesirable drag forces. Combining wing warp with canard tilt provide a 
satisfactory means for large heading changes. Although nonlinear control techniques were required, the large "apparent" damping helped provide docile flight behavior.

Recently, projected fighter aircraft designs such as the Saab JAS39 Gripen, the U.K. ACA, the French ACX, and the IAI Lavi use a variation of the canard surface in a "close-coupled" arrangement. The foreplane is closecoupled when it is placed a relatively short distance ahead and slightly above the main wing such that the wake (vortices) shed from the lifting canard reenergize the flow over the inner portions of the wing. This tends to suppress vortex bursting, thereby promoting more linear lift and pitching moments to high $A O A$ beyond the nominal $C_{L_{\max }}$. In particular, the delta wing planform which offers lower wave drag over a wide range of Mach numbers can benefit from the canard by providing better lift distributing (higher L/D) in transonic flow conditions and increased usable lift in takeoff and landing.

The delta planform for fighters originated in Germany during WW II on the ME 163. Other countries soon used this planform which offered good high-speed (supersonic) potential. The low-aspect delta planform has disadvantages in landing because of its low lift curve slope. Large pitch attitude is required to generate desirable values of lift for landing. On approach, pitch attitude is constrained by pilot visibility and ground geometry clearance, and unless very low wing loading is employed, high approach speeds are required. Cambering the delta to increase lift at a given $A O A$ by trailing edge flaps normally has a fundamental limitation in trimming the increased nose-down pitching moment. This can be overcome by using the canard (foreplane) as employed on the Viggin fighter.

One of the first fighter delta configurations to use the close-coupled canard is the Saab Viggin, ${ }^{16}$ which made its first flight in Eebruary 1967. 
This aircraft required high Mach number performance for its interceptor role combined with good low-speed capability to allow its use on short runways or roads in Sweden. A three-view drawing of the Viggin (Fig. 13) shows geometric features which have been carefully selected to accomplish these goals. The wing is low-aspect-ratio with the outer panels swept $60^{\circ}$ for low wave drag at high supersonic speeds. The inner wing panels use less sweep to improve pitching moment characteristics in the downwash of the canard in the transonic range. Elevons are used on the wing for roll and pitch control. The elevons are deflected down for low-speed operation, their effectiveness is increased by using blowing boundary layer control. The canard is low-aspect-ratio also, carefully selected to provide high-maximum-lift and reliable flow behavior to high $A O A$ as well as at large sideslip angles. The canard incidence is fixed. The rear surface or flap is movable to provide only a trim function and is therefore not a maneuvering (pitch) control. There are two positions of the canard flap, a mid position for takeoff and full-down for landing. These positions are actuated by the landing gear control level; thus the pilot work load is minimized--the flap is mechanically connected to the landing gear lever.

An interesting design consideration of the canard was a requirement to remain unstalled over a larger $A O A$ range than the main wing. Thus, instead of providing the usual passive stall limiting where the canard stalled before the wing, its primary function was to enhance overall lift to reduce touchdown speeds. This was achieved by wind tunnel testing to determine a suitable (trapezoidal) planform and placement (close-coupled and above) related to the main wing. Upwash from the main wing provided favorable (interference) flow conditions such that $C_{\mathrm{L}_{\max }}$ of the canard was increased by $40 \%$ and the $A O A$ 
for $C_{L_{\max }}$ for the aircraft extended well beyond that used in landing approach.

The low-speed characteristics of this configuration are considered to be satisfactory. Initially, a reduction in stability occurred at $A O A$ of $8^{\circ}$, which produced an unacceptable nose-up trim change. This was caused by flow separation at the outer wing panel. A sawtooth (notch) leading edge modification cured the problem, and pitch stability is linear up to $30^{\circ} \mathrm{AOA} . \mathrm{C}_{\mathrm{L}_{\max }}$ occurs slightly above $A O A$ of $30^{\circ}$ after which a small pitch instability (pitch-up) takes place followed by a stable slope out to very large $\left(90^{\circ}\right)$ AOA. Both $C_{N_{B}}$ and $C_{\ell_{B}}$ are unstable beyond $30^{\circ} A O A$. Vortices shed from the canard at high AOA strongly influenced flow at the vertical tail and lateral directional stability changed. Improvements in lateral/directional characteristics were achieved by reducing dihedral of the canard from $10^{\circ}$ to $0^{\circ}$. Touchdowns are made in the $A O A$ range of $12^{\circ}$ to $16^{\circ}$. Beyond $16^{\circ}$ flight path control deteriorates because of low Dutch roll damping and power response problems associated with flying on the back side of the power required curve. Studies have been made for improving flight path control by using the canard flap in conjunction with the elevons for direct lift control. The aircraft can be flown comfortably to $25^{\circ} \mathrm{AOA}$; departure tendencies occur beyond $38^{\circ} \mathrm{AOA}$.

The high-speed performance of this canard aircraft is strongly affected by the tradeoff between stability and performance. Subsonic trim drag is determined by the wing/fuselage pitching moment. Optimum subsonic trim drag therefore requires that the c.g. be located such that zero or low positive tail loads are needed. For an aft-tail fighter aircraft, the tail is sized to provide positive pitch stability, adequate control power for more wheel liftoff, and for maneuvering at supersonic speeds. The same sized tail placed 
forward at the same moment arm provides similar control power for more wheel lift-off; however, pitch stability has changed sign. Thus, the canard operating in the upwash of the wing is destabilizing and the c.g. must be moved forward for a stable $\mathrm{C}_{\mathrm{m}_{\alpha}}$. This obviously requires the canard to carry a significant proportion of the total lift, roughly 15\%, with a corresponding induced drag penalty. Going to supersonic speeds, the aerodynamic center moves aft approximately $15 \%$ mean aerodynamic chord for this wing planform. This increase in stability further increases the up-load requirement of the canard, with severe trim and maneuver drag penalties. If the c.g. is located for minimum supersonic trim drag (approximately $C_{m_{\alpha}}=0$ ), the aircraft becomes highly unstable upon returning to subsonic flight. The obvious solution is to provide artificial pitch stability, a feature not provided in the Viggin control system. Thus the Viggin aircraft pays a high-speed performance penalty for the canard which would be unacceptable if the aircraft were used in an air superiority role.

The most recent example of canard technology is the Grumman X-29A forward-swept-wing aircraft (Fig. 14). This advanced aircraft features an aeroelastically tailored wing, relaxed static stability (RSS), a digital fly-bywire (FBW) flight-control system, and a thin (5\% thickness/chord) supercritical airfoil with discrete variable camber. Pitch control is obtained by an all-moving (variable incidence) close-coupled canard. Strakes added to the wing root trailing edge use flaps for pitch trim--helping to raise the nose wheel for takeoff and increase overall lift in approach. Full-span flaperons are used also. The forward-swept wing can be expected to provide significantly higher $L / D$ maneuvering performance at transonic speeds and improved low-speed handling. 17 
Forward-swept wings on military aircraft originated in Germany in WW II on the Junkers JU-287 bomber and later in the 1960s on the HFB-300 Hansa business jet. Because of the natural inboard flow of the boundary layer at high AOA on a forward-swept wing, inboard lift suffers adversely. Fences, leading edge vanes, or large amounts of wing twist delay flow separation to some degree. A close-coupled canard can unload the inboard wing area by virtue of the downwash from the forward lifting surface. The current trend to maneuver fighter aircraft at very high AOA for good air-combat effectiveness places special demands on the canard pitch control as described for the X-29A in the following discussion.

One design condition for the $X-29 A$ is Mach 0.9 at $30,000 \mathrm{ft}$, with the canard sized for maneuvering at this subsonic speed. To provide minimum trim drag at supersonic speeds, RSS is used; the c.g. is located for neutral (wing) fuselage) pitch stability. Positive (lifting) loads are provided by the canard for supersonic maneuvering, thus improving flight efficiency. A $40 \%$ forward shift of the aerodynamic center occurs for this planform in going from supersonic to subsonic flight, resulting in a $35 \%$ negative static margin (pitch instability). The short period has a time to double amplitude of $0.85 \mathrm{sec}$. This degree of instability would normally be unflyable because of the pilot's inherent limitations in frequency response and phase lags. Artificial stability can be provided by a stability-augmentation system using $A O A$ and pitch-rate feedbacks. A digital FBW flight-control system provides a desired pitch rate for maneuvering. Overshoots or divergences are prevented by the addition of pitch damping. The success of this system depends to a great extent upon good pitch control effectiveness over a large AOA range discussed next. 
Wind tunnel tests ${ }^{18}$ indicate that with canard off, initial wing stall occurs at the wing root at about $12^{\circ}$ AOA. Pitching moment data show neutral to slightly unstable static stability in the AOA range of $15^{\circ}$ to $40^{\circ}$. Addition of the canard significantly increases the level of instability in the $A O A$ range of $30^{\circ}$ to $60^{\circ}$, depending upon canard incidence. Good pitch-control effectiveness is retained over a wide $A O A$ range by virtue of the large (variable incidence) travel of the canard $\left(-60^{\circ}\right.$ to $\left.30^{\circ}\right)$, and the aircraft can be trimmed over the $A O A$ range from $10^{\circ}$ to $70^{\circ}$. The only deficiency noted was marginal nose-up pitch control below $20^{\circ}$ AOA because of canard stall. A fixed-incidence canard would stall and lose trim capability over this large AOA range. Since the strake flaps provided constant pitching moments over the entire $A O A$ range, they could be programmed to complement canard control.

The canard, by virtue of its flow interaction with the wing, influences the lateral/directional stability and control characteristics. Wind tunnel tests show a degradation in both lateral and directional static stability at high canard deflections due to a blanketing of flow over the inboard portion of the wing. At lower canard deflections, the canard enhanced lateral and directional stability up to $30^{\circ} \mathrm{AOA}$. Lateral control was influenced by canard-induced wing-flow changes. At low canard deflections aileron effectiveness was improved in the $A O A$ range of $10^{\circ}$ to $60^{\circ}$ as a result of favorable flow effects from the canard over the inboard portion of the wing. At large negative (nose-down) deflections, lateral control effectiveness was reduced, presumably because of inboard wing stall resulting from adverse canard flow (decreased downwash). Directional stability and control effectiveness was influenced by canard deflection. Rudder-control effectiveness decreased markedly when inboard wing flow deteriorated when nose-down canard deflections 
were used. Directional control above $40^{\circ} \mathrm{AOA}$ would be expected to be unsatisfactory.

As previously discussed for the XP-55 aircraft, tumbling, a sustained autorotative pitching gyration, was identified as a potential problem for the X-29A aircraft. Tumbling susceptibility is accentuated by effects of RSS, canard control, and high pitch agility requirements. Tests were conducted on an $X-29 A$ model $^{19}$ in a high $A O A$ condition with wing flaps down, strake flaps down, and canard deflected $-60^{\circ}$ (full nose-down) to simulate a stall recovery (see Ref. 10). When released from a nose-high $\left(A O A=-180^{\circ}\right.$ ) position, the model underwent a nose-down autorotative pitching motion. The model exhibited complex cyclic variations in linear and angular rates varying from $20-200 \% / \mathrm{sec}$. Asymmetry in control settings caused unusual gyrations out of the pitch plane. Although this aircraft has large pitch-control power, variations in canard deflection did not alter the tumbling behavior or result in recovery. Deflection of the strake flaps to oppose the tumbling were effective in damping the motion, suggesting their use as a method of controlling tumble. Although the model tests indicated a tumble tendency with controls fixed, it is unlikely that the highly augmented $X-29 A$ control system would allow pitch angular excursions to build up to the point where tumbling would occur.

\section{Concluding Remarks}

A review of stability and control characteristics of canard configurations showed the need for careful consideration to design details to ensure satisfactory handling qualities. The greatest challenge was the need to provide good pitch stability characteristics and adequate pitch-control power in 
the stall and post-stall regions. Compared to conventional designs, a more accurate control of $\mathrm{c.g}$. position is required to provide the beneficial passive stall AOA limiting inherent in the canard layout. Modern control technology should benefit future canard designs to a greater advantage by allowing the use of relaxed static stability (RSS) without compromising handling qualities. 


\section{References}

${ }^{1}$ Lennon, A., CANARD - A Revolution in Flight, Aviation Publishers, September 1984.

${ }^{2}$ McGeer, T. and Kroo, I., "A Fundamental Comparison of Canard and Conventional Configurations," Stanford University, Stanford, California. AIAA Journal of Aircraft, Vol. 20, No. 11, November 1983.

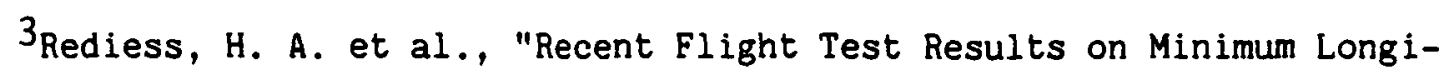
tudinal Handling Qualities for Transport Aircraft," presented at the FAUSST VIII Meeting, Washington, D.C., January 1971.

4 Wasserman, R. and Mitchell, J. F., "In-Flight Simulation of Minimum Longitudinal Stability for Large Delta-Wing Transports in Landing Approach and Touchdown," AFFDL-TR-72-143, February 1973.

$5_{\text {Warner, E. P. and Norton, F. H., "Preliminary Report on Free Flight }}$ Tests," NACA Report 70, 1920.

${ }^{6}$ Soule, H. A., "Preliminary Investigation of the Flying Qualities of Airplanes," NACA Report 700, 1940.

7 McFarland, M., ed., The Papers of Wilber and Orville Wright, McGrawHill, New York, 1953.

${ }^{8}$ Culick, F. E. C. and Jex, H. R., "Aerodynamics, Stability and Control of the 1903 Wright Flyer," Project Report WF84/09-1, Systems Technology, Inc., Paper No. 359, September 20, 1984.

${ }^{9}$ Perkins, C. D., "The Development of Airplane Stability and Control Technology," 1969 von Karman Lecture, Journal of Aircraft, Vol. 7, July-August 1970, pp. 290-301.

${ }^{10}$ Boyne, W. J., Col. UASF (Ret), "Weird Wonderful Airplanes," Air Force Magazine, 1 June 1975. 
${ }^{11}$ Stone, R. W., Jr. and Bryant, R. L., "Summary of Results of Tumbling Investigations Made in the Langley 20-Foot Free-Spinning Tunnel on 14 Dynamic Models," NACA RM No. L8J28, 1943.

${ }^{12}$ Rutan, B., "Tales of the Three EZ's," Sport Aviation, February 1980, pp. 34-39.

13Yip, L. P., "Wind-Tunnel Investigation of a Full-Scale CanardConfigured General Aviation Airplane," NASA TP-2382, March, 1985.

${ }^{14}$ Chambers, J. R., Yip, L. P., and Moul, T. M., "Wind-Tunnel Investigation of an Advanced General Aviation Canard Configuration," NASA Langley Research Center TM-85760, April 1984.

$15 \mathrm{Jex}, \mathrm{H}$. R. and Mitchell, D. G., "Stability and Control of the Gossamer Human-Powered Aircraft by Analysis and Flight Test," NASA CR-3627, October 1982.

${ }^{16} \mathrm{Kl}$ inker, 0 . and Dahlstrom, E., "SAAB Viggin and Its First Test Flight," SETP 12th Symposium Proceedings, September 26-28, 1968.

17 Ishmael, S. D. and Wierzbarowski, T., "X-29 Initial Flight Test Results," The Society of Experimental Test Pilots, 29 Symposium Proceedings, September 25-28, 1985

18 Murri, D. G., Nguyen, L. T., and Grafton, S. B., "Wind-Tunnel FreeFlight Investigation of a Model of a Forward-Swept-Wing Fighter Configuration," NASA TP-2230, February 1984.

${ }^{19}$ Whipple, R. D., Croom, M. A., and Faars, S. P., "Preliminary Results of Experimental and Analytical Investigations of the Tumbling Phenomenon for an Advanced Configuration," AIAA Paper 84-2108, 1984. 


\section{Eigure Captions}

Fig. 1 Summary of pilot comments on dynamic stability.

Fig. 2 Pilot rating vs time to double amplitude.

Fig. 3 Two views of Wright 1903 Flyer.

Fig. 4 Three views of Curtiss XP-55.

Eig. 5 Curtiss XP-55 in flight.

Fig. 6 Inverted crash landing of curtiss XP-55.

Fig. 7 Three views of VariEze model.

Fig. 8 Pitching-moment characteristics of VariEze model.

Fig. 9 Three views of PAT-1 model.

Fig. 10 Pitching moment characteristics of PAT-1 model for aft c.g. location, power off.

Fig. 11 Effect of elevator deflection on deep-stall trim condition with aft c.g. location.

Fig. 12 Three views of Gossamer Albatross. 
Fig. 13 Three views of Saab Viggen canard fighter.

Fig. 14 Three views of Grumman X-29A fighter. 


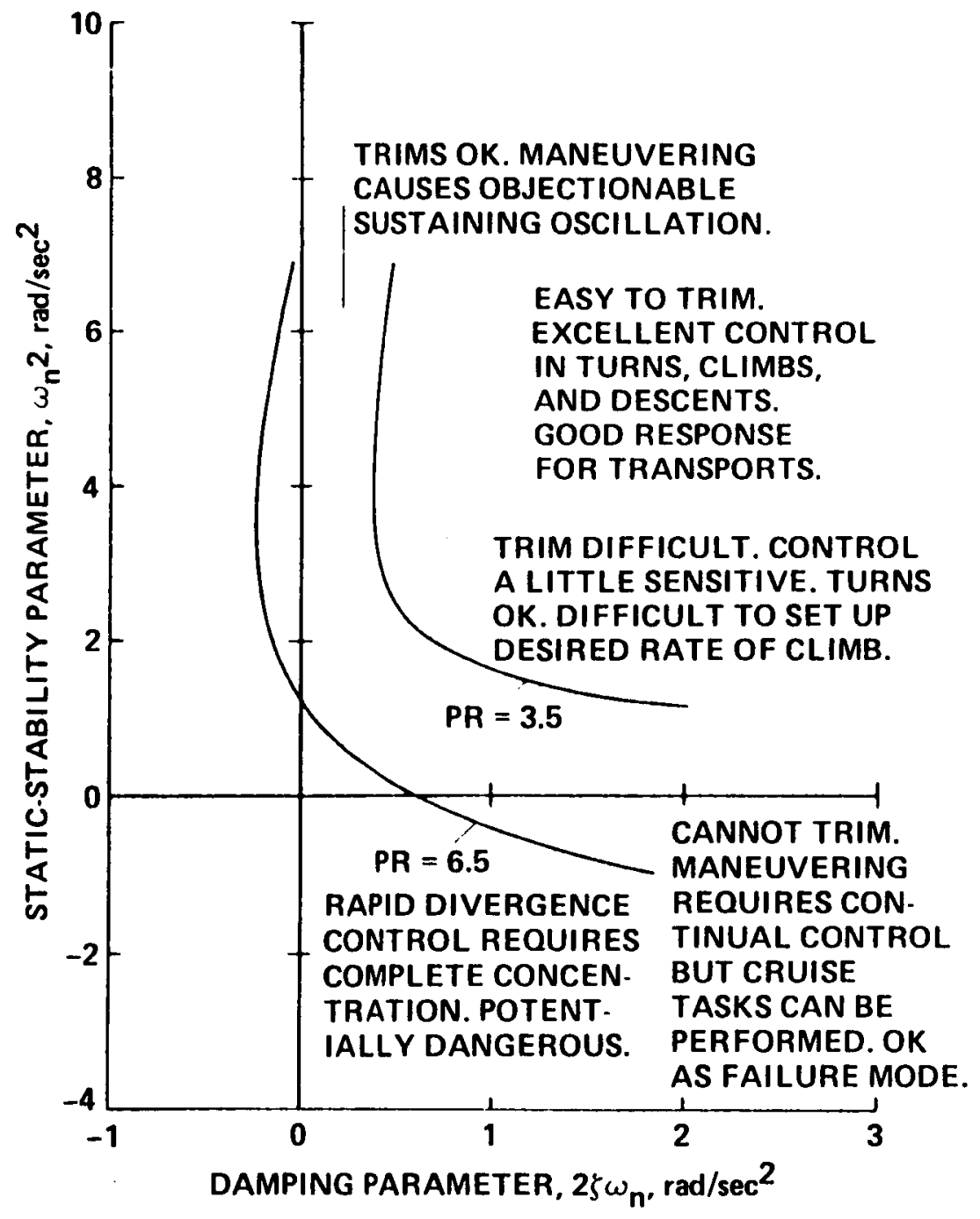

Fig. 1 


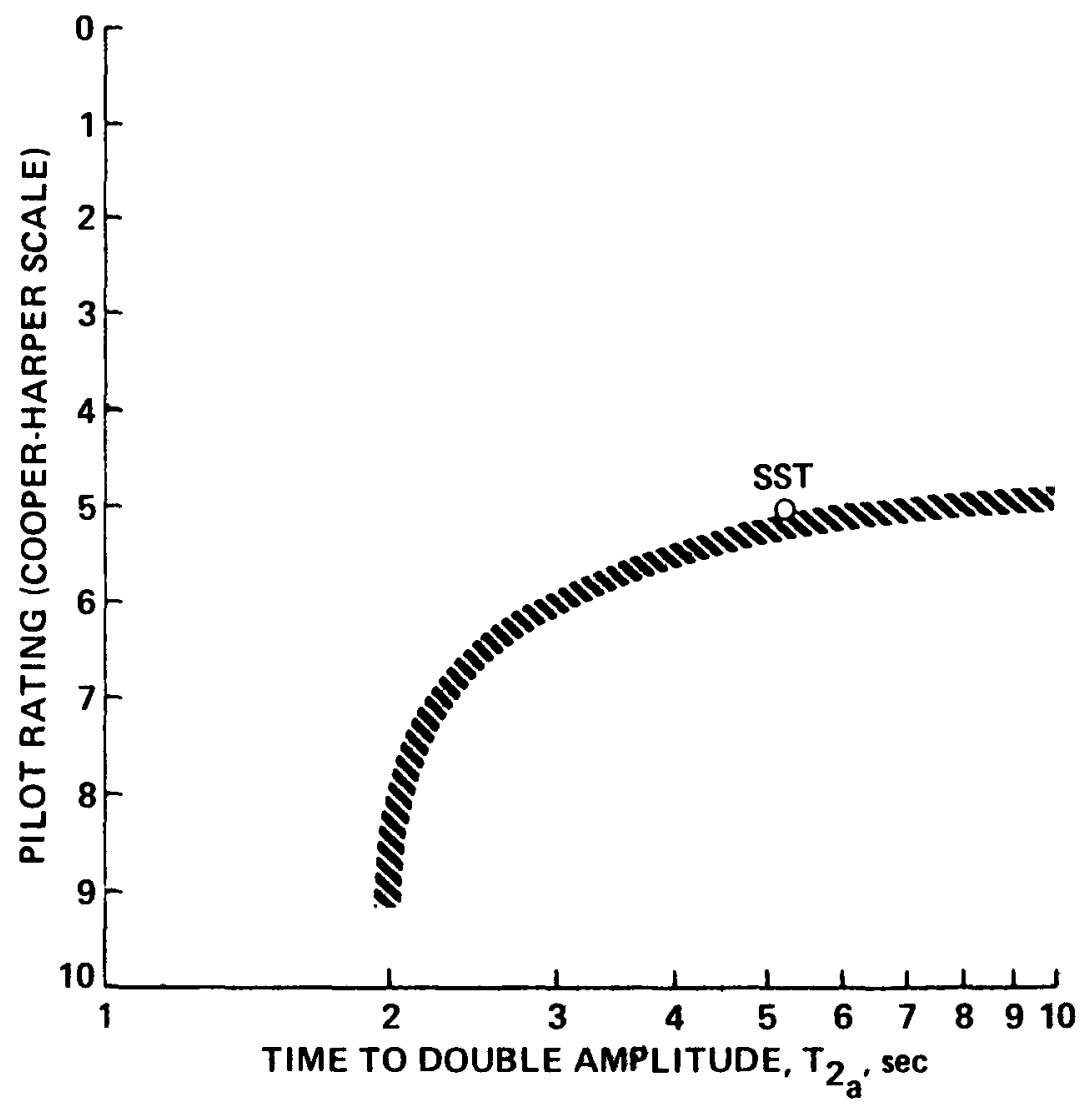

Fig. 2 


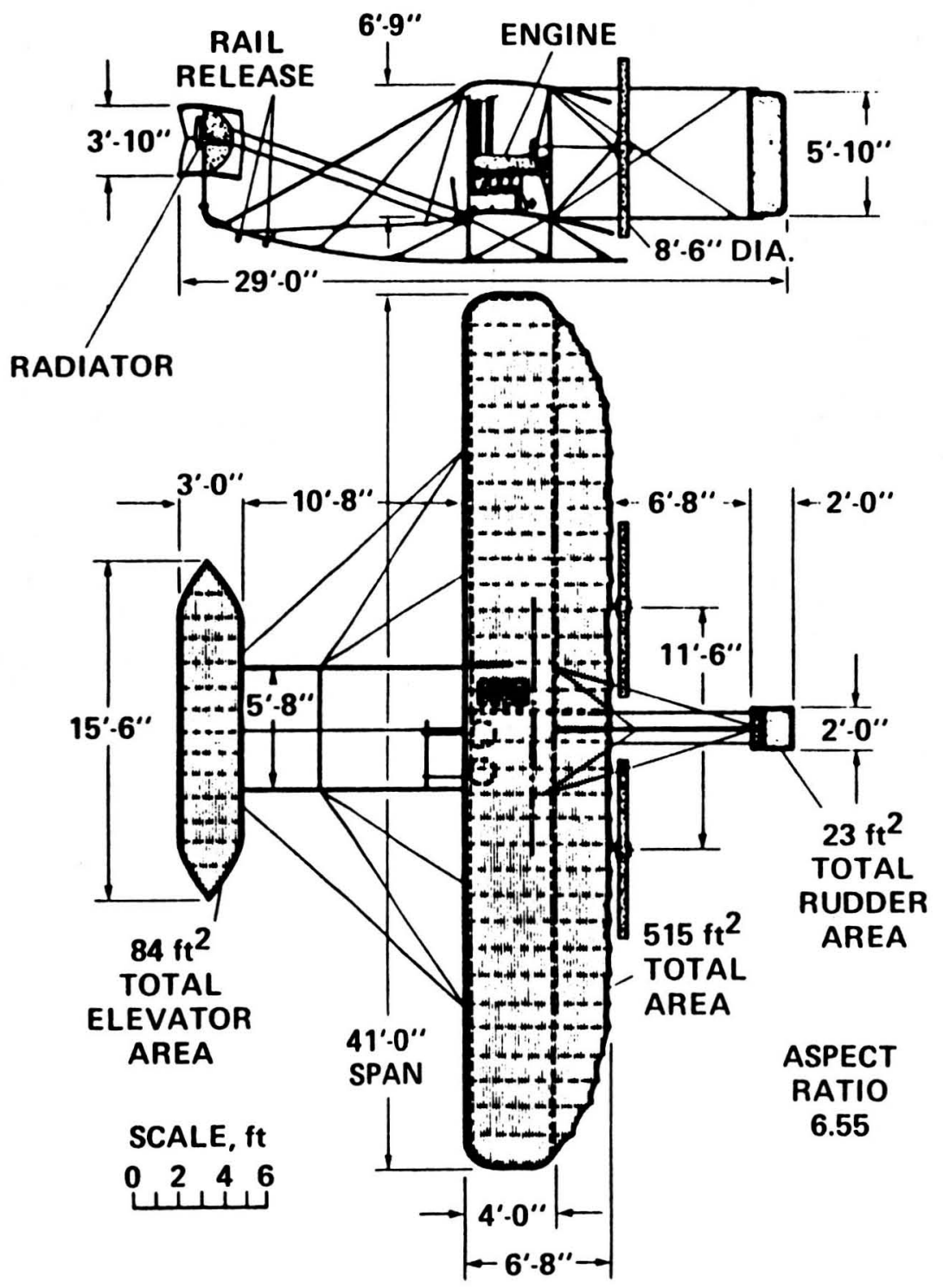

Fig. 3 
ORIGNARE PAGE DS

OF POOR QUAATTY

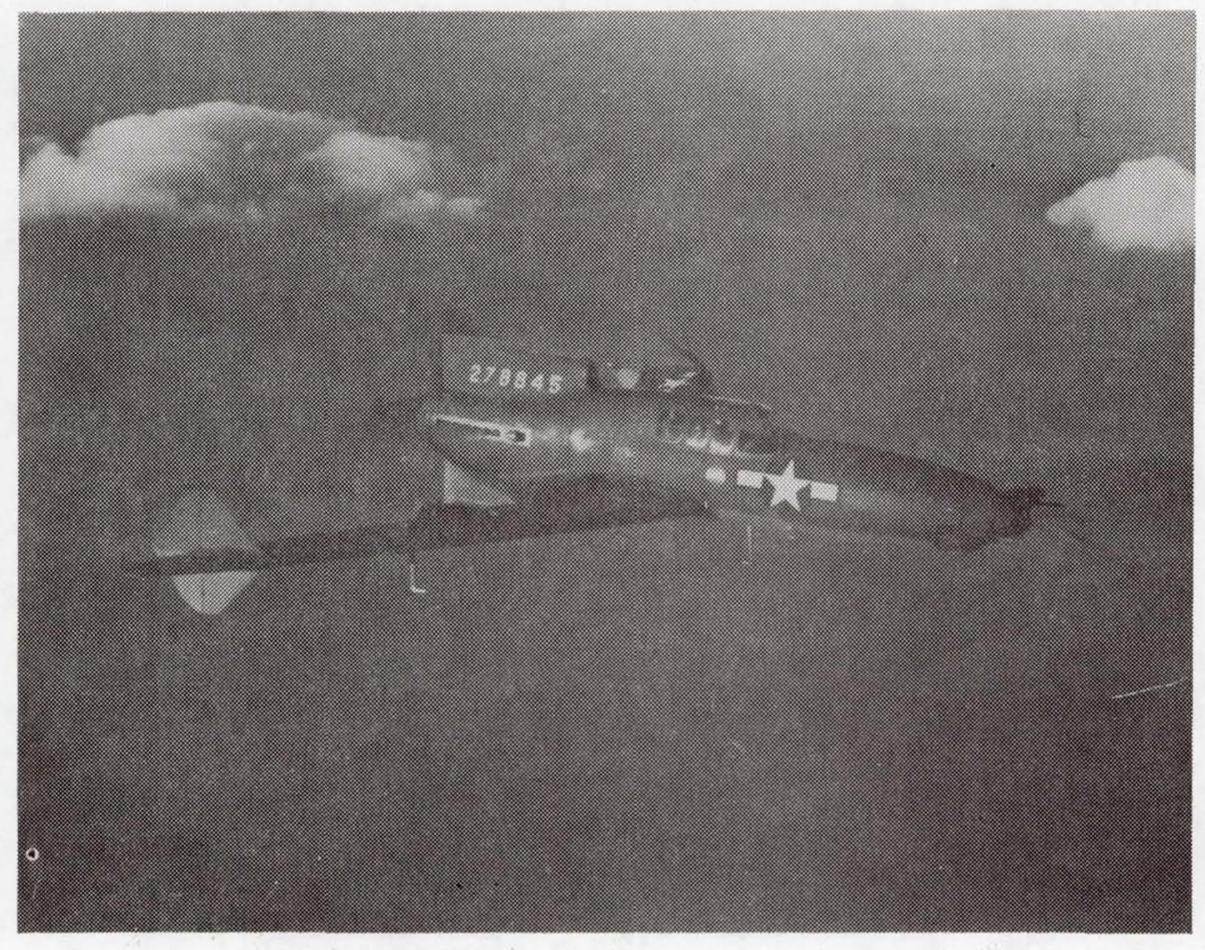

Fig. 4 

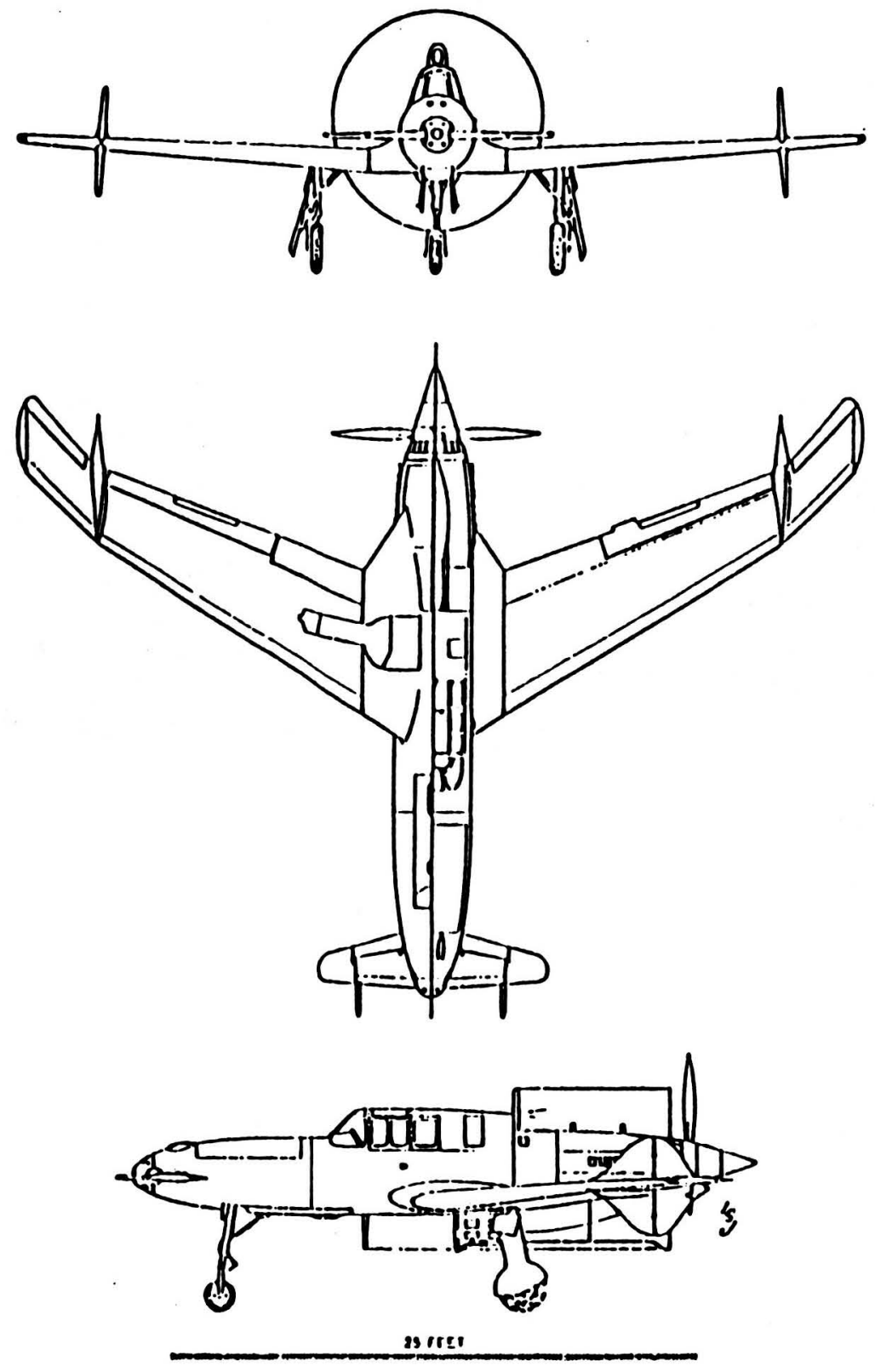

Fig. 5 
ORIGINAL PAGE IS

OF POOR QUALITY

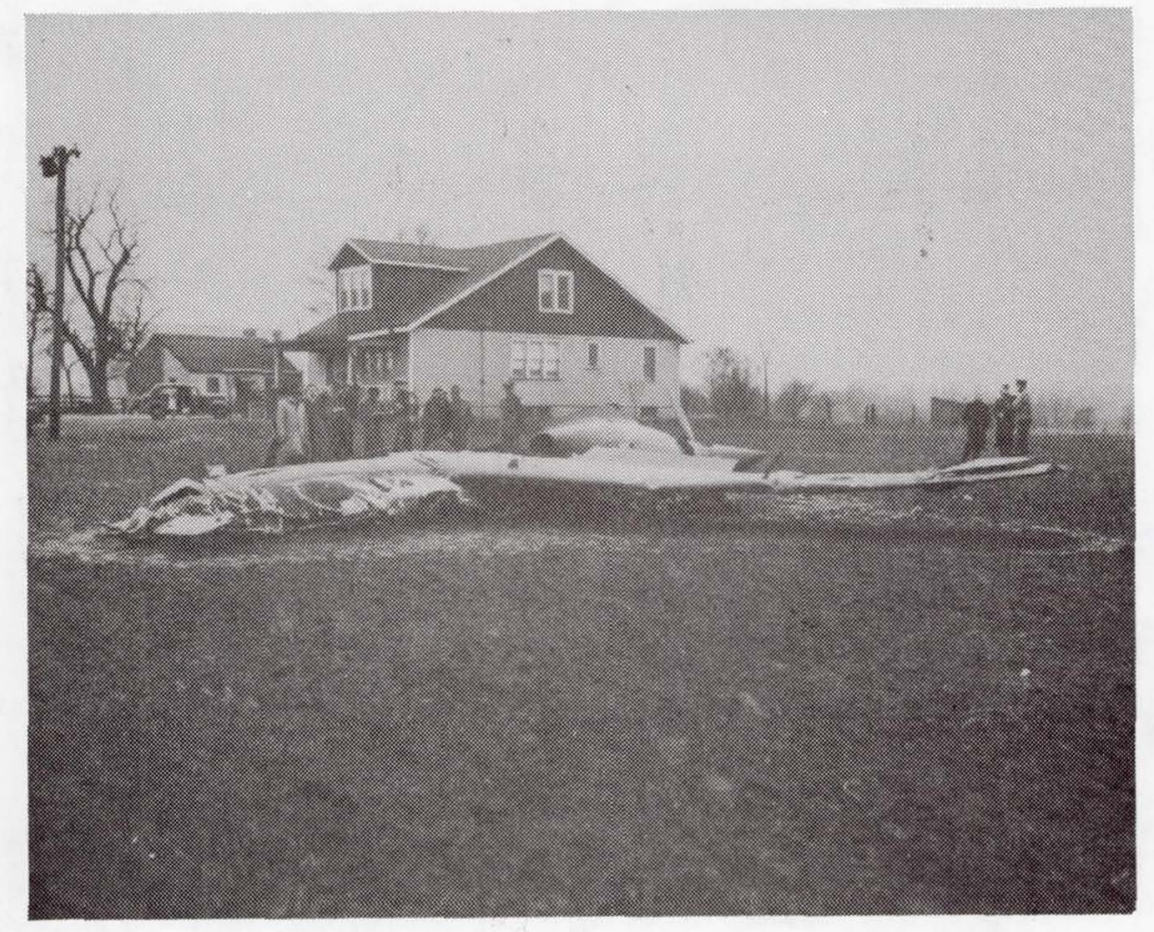

Fig. 6 


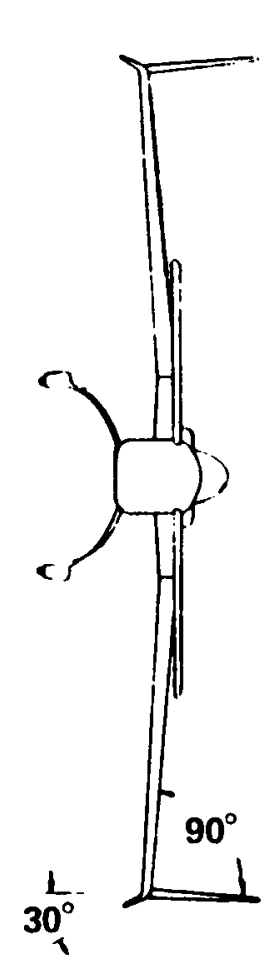

FS (161.5)
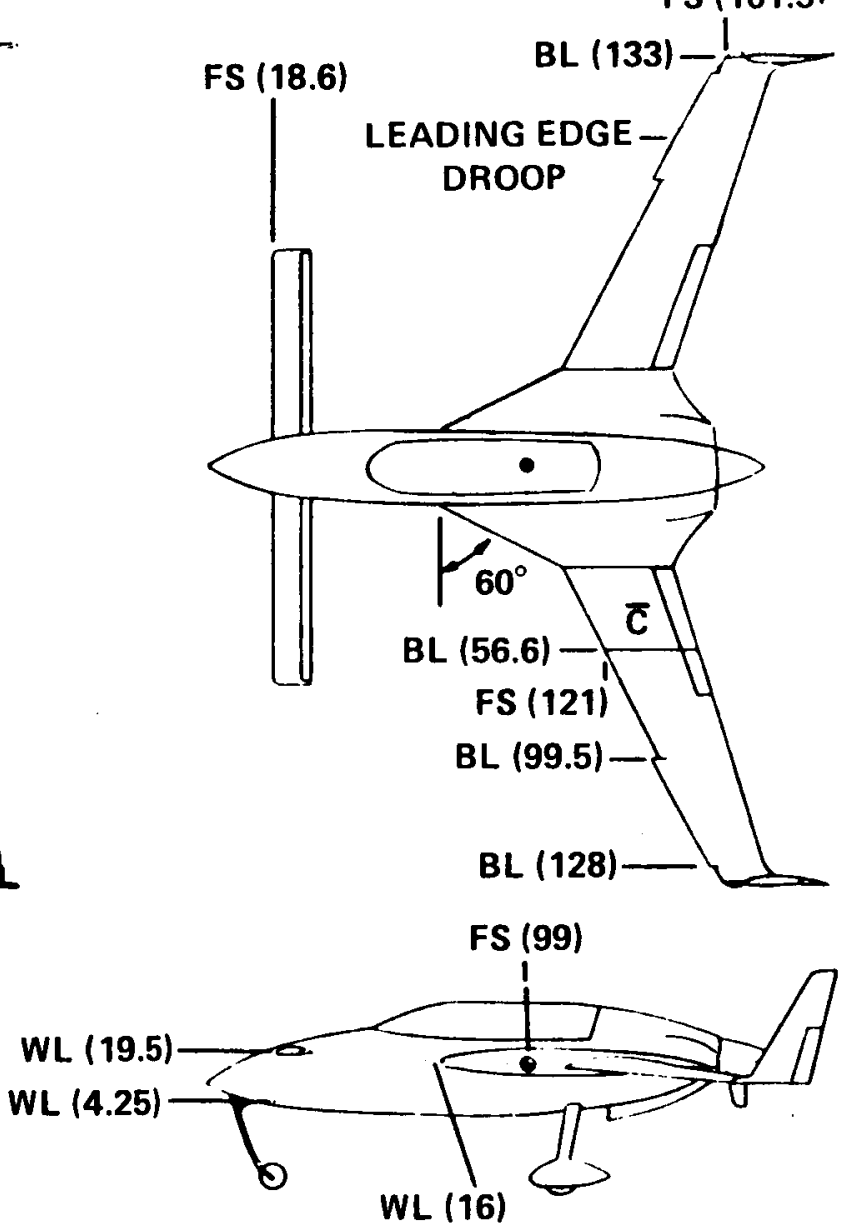

Fig. 7 


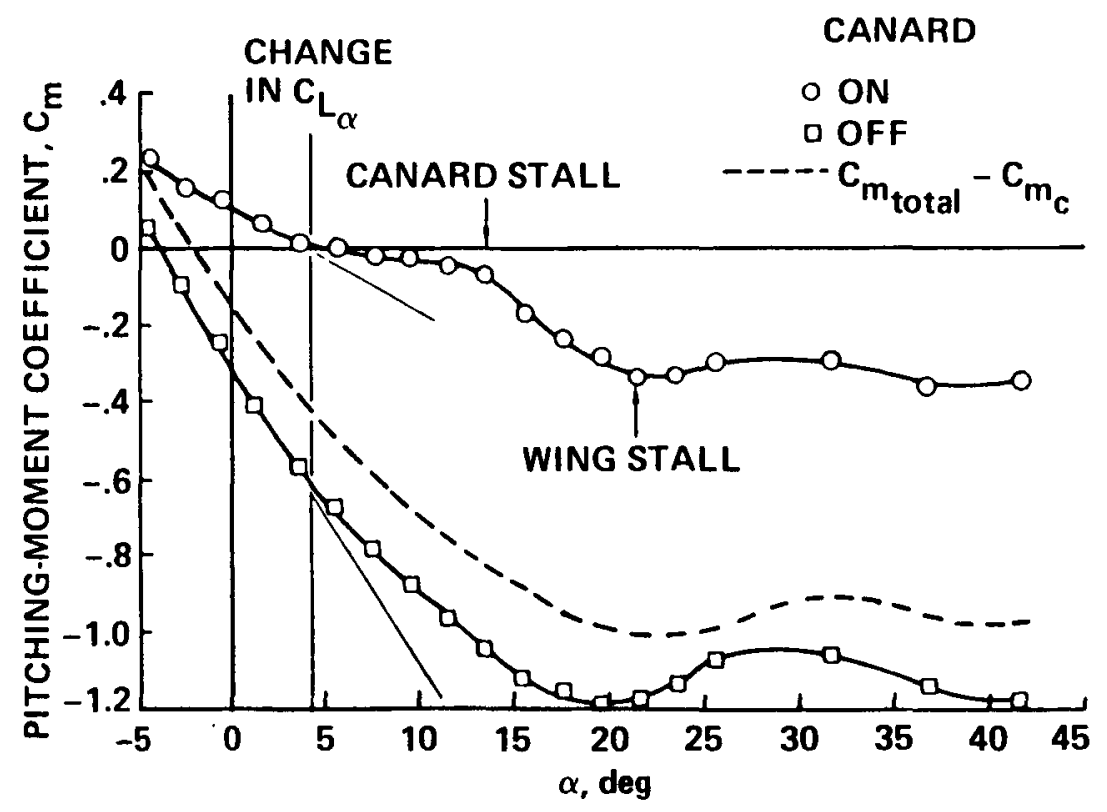

Fig. 8 


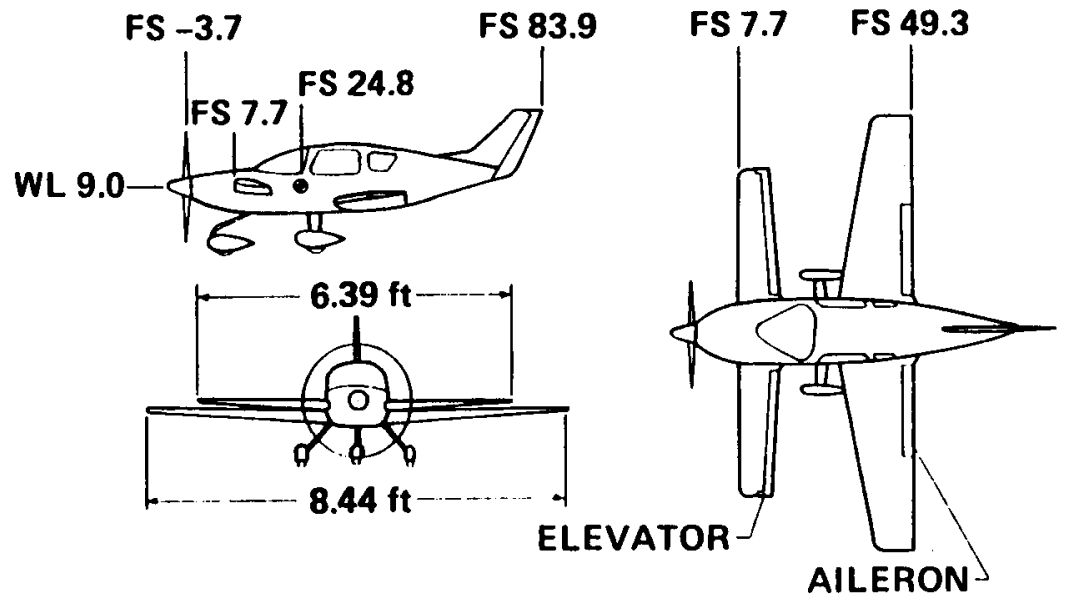

Fig. 9 


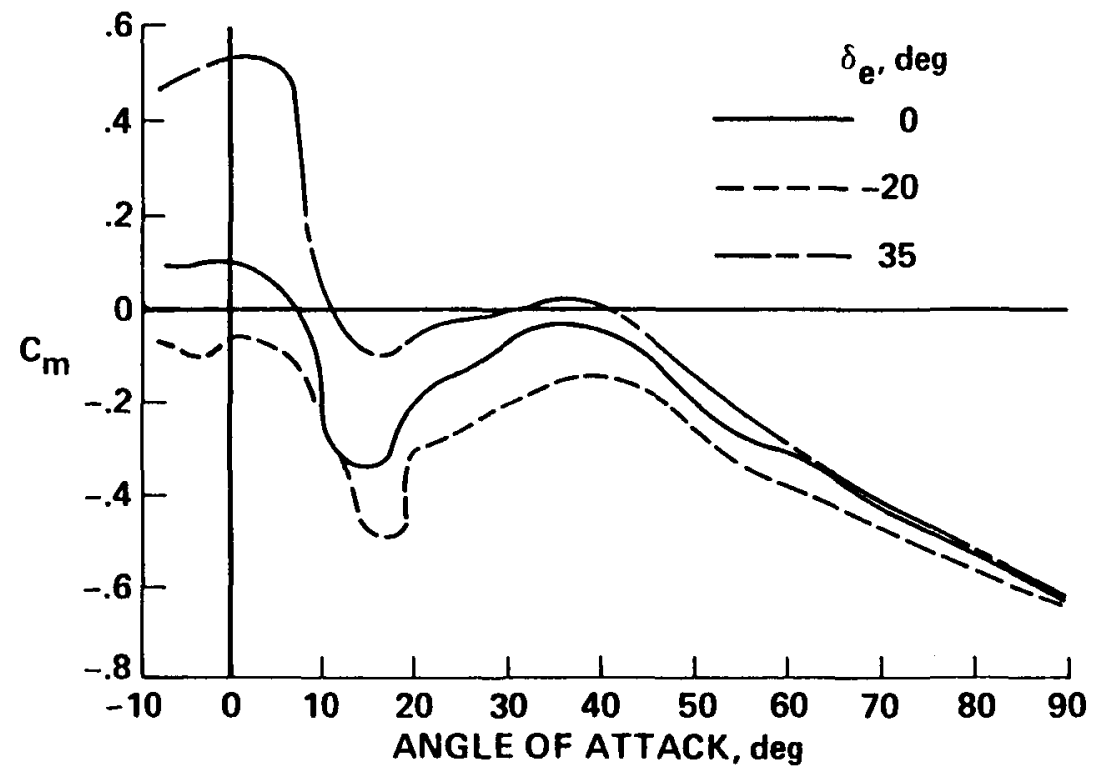

Fig. 10 


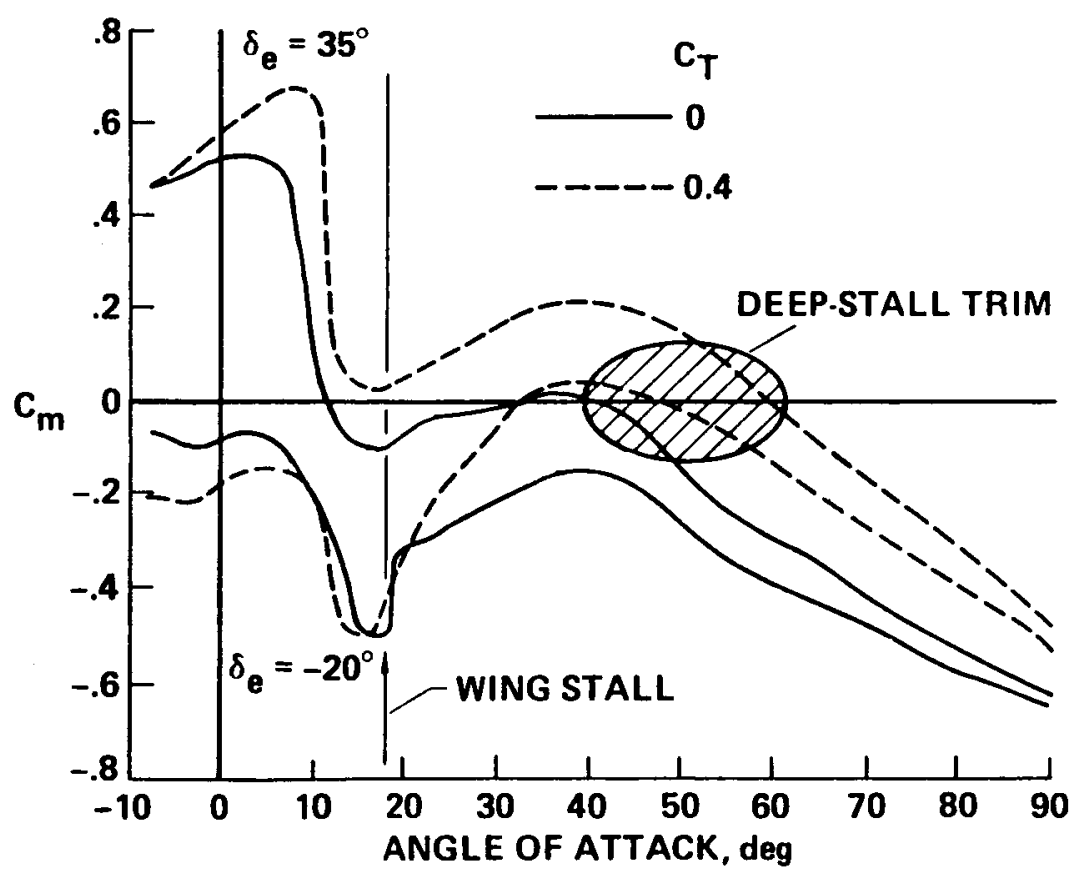

Fig. 11 


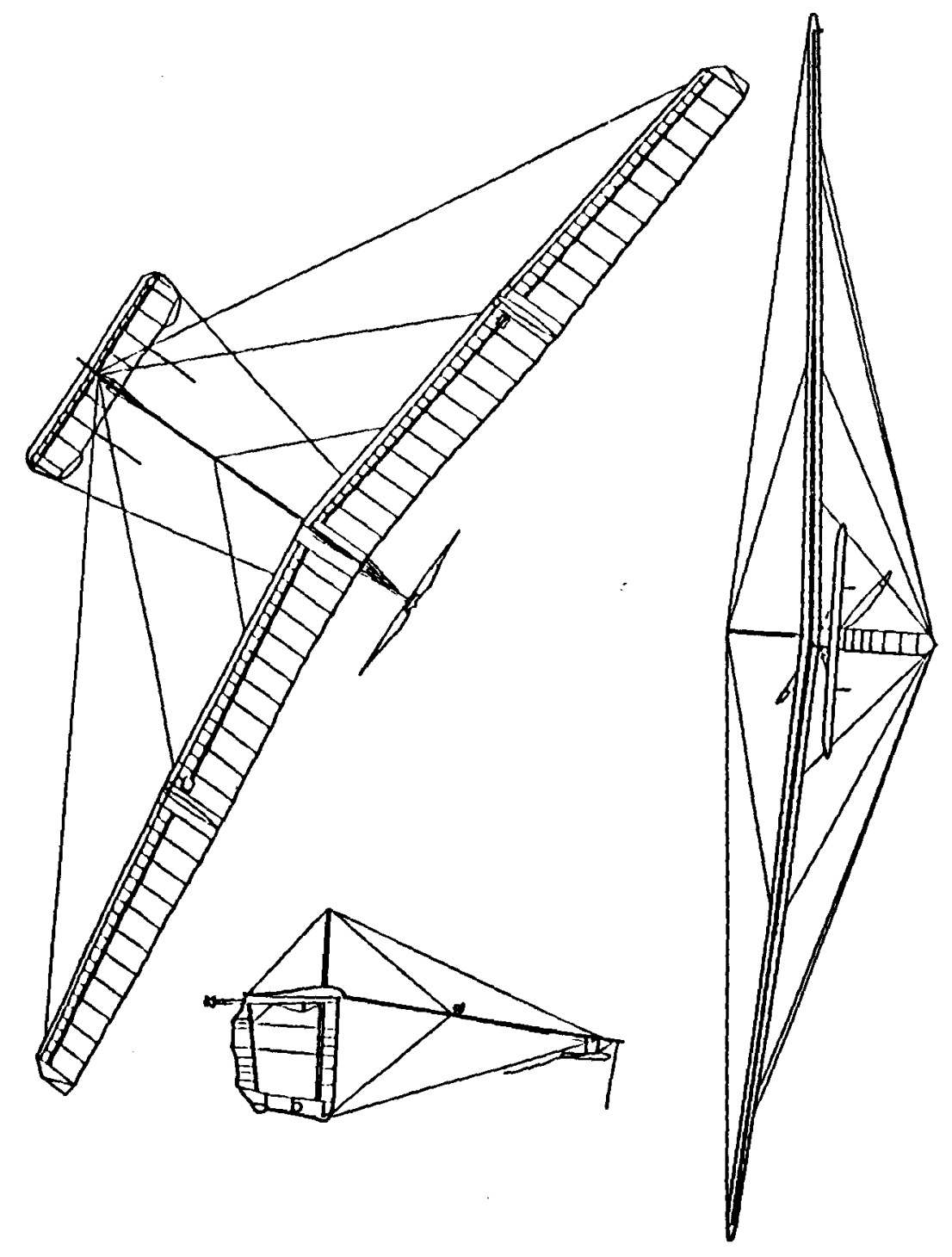

Fig. 12 


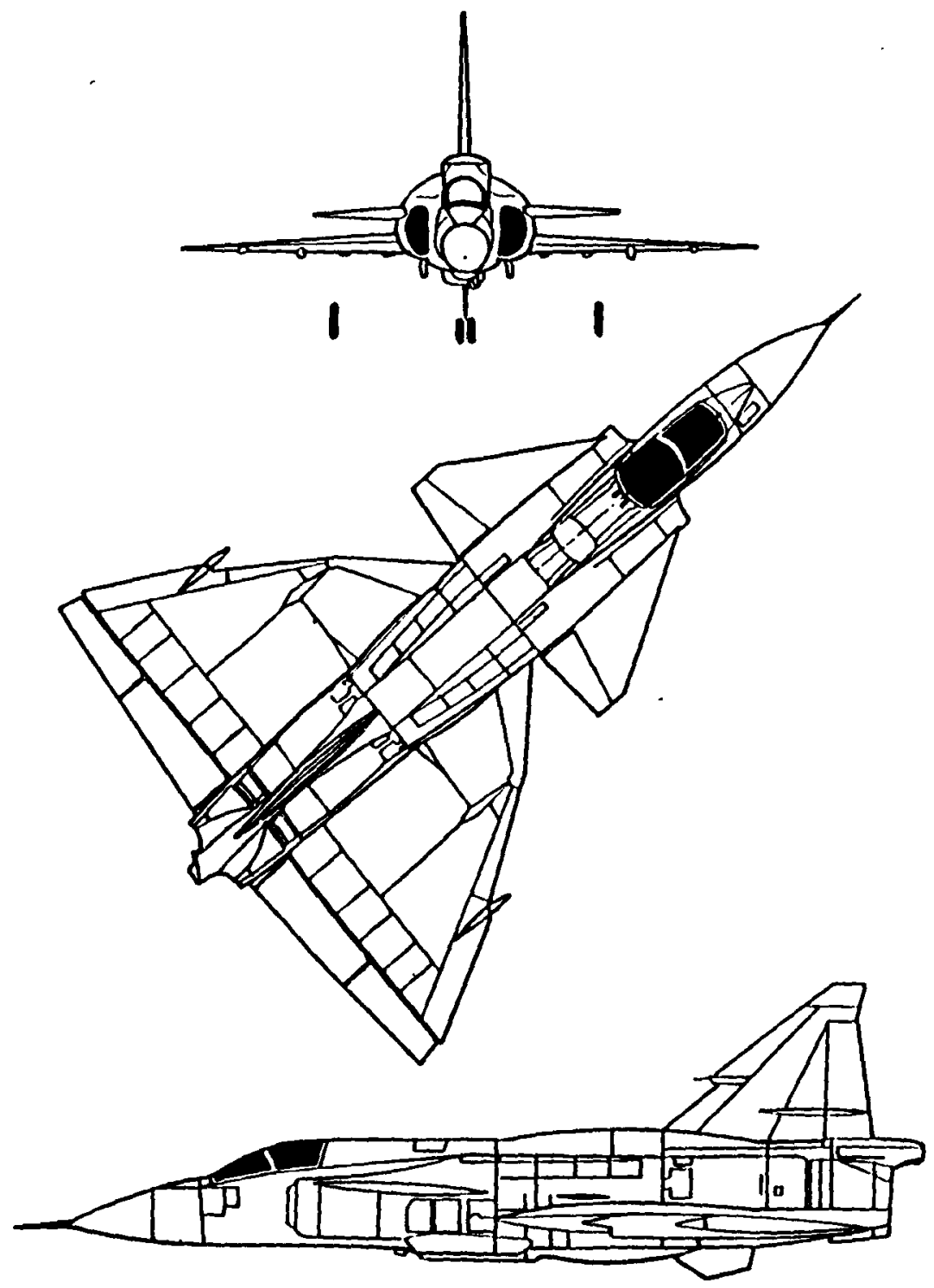

Fig. 13 


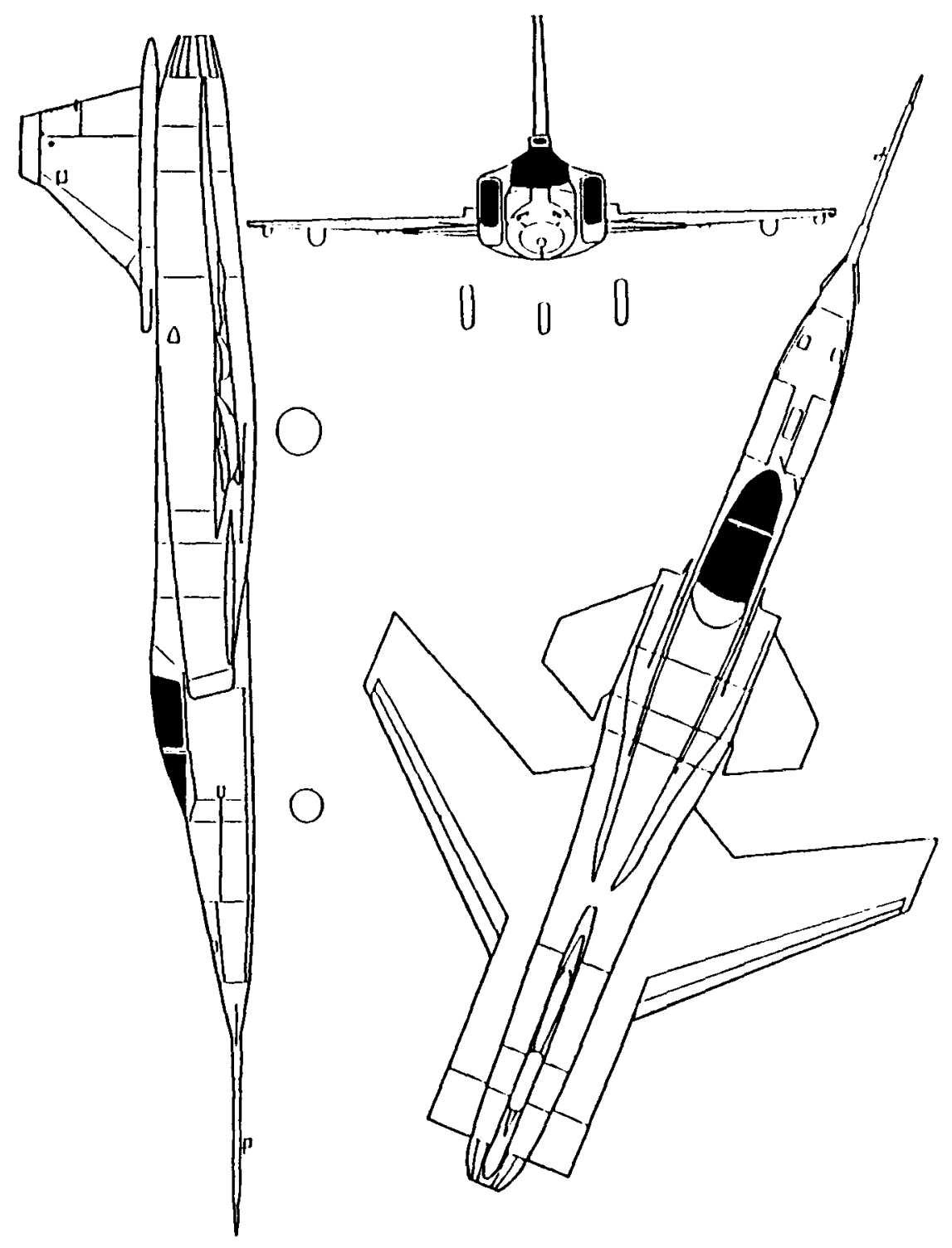

Fig. 14 


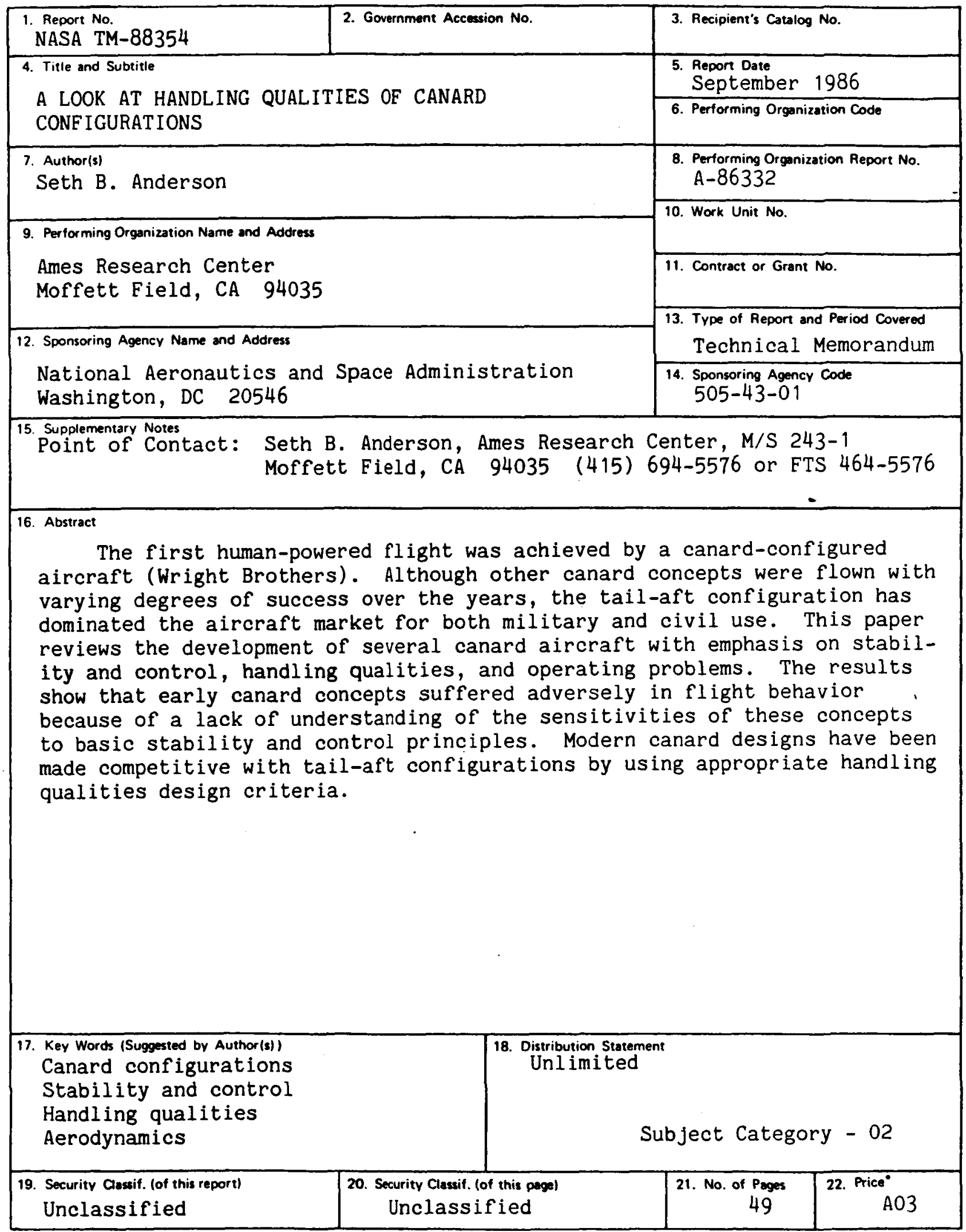

-For sale by the National Technical Information Service, Springfield, Virginia 22161 